\title{
Research on Citizen Emergency Alarm System
}

\author{
Jinlan Guo \\ Computer Teaching Department, Shanghai University of Political Science and Law, Shanghai, China.
}

Keywords: emergency management; social media; alarm system

\begin{abstract}
The purpose of this paper is to study changes in information dissemination and communication methods among government departments, rescuers and people afflicted by disasters during the processes of emergency management. In the mobile Internet environment, a citizen emergency alarm system should be established from the perspective of the government, in order to integrate resources from various government departments, and provide victims as well as rescuers with quick, real and effective information and services. Through this system, the government can better cope with unexpected events, and improve its administrative capability. Public trust of government can also be enhanced.
\end{abstract}

\section{Introduction}

The Master State Plan for Rapid Response to Public Emergencies stipulates that, public emergencies are generally divided into four levels: extremely large, major, large and general according to the natures of public emergencies, orders of severity, controllability and influence scopes. According to the generating processes, mechanisms and natures, public emergencies can be divided into four categories. The first category is natural disasters, mainly includes floods, droughts, meteorological disasters, earthquake, geological disasters, ocean disasters, biological disasters as well as forest and grassland fires. The second category includes safety accidents happened in companies, traffic accidents, public facilities and equipment accidents, environmental pollution and ecological damage. The third category is public health events, includes infectious diseases, unidentified diseases, video safety and occupational hazards, animal epidemic, and other events which serious impact public health. The fourth category is social security incidents, including terrorist attacks, economic security incidents and foreign related emergencies. This paper mainly discusses various public emergencies in cities, and explores an emergency alarm system based on modern information means.

China is in the process of urbanization; the efficiencies of government management and service cannot meet the requirements. Hidden dangers and concentrated population pose threat to cities' disaster resistance abilities. At 23:35 pm on December 31, 2014, a swarm and jostlement accident occurred at Chen Yi Square of the Bund in Huangpu District, Shanghai, killing 35 people and injuring 43. On November 15, 2010, a fire broke out in a tall building located at 728 Jiaozhou Road, Shanghai. The number of victims was 58. In Beijing, Wuhan, Handan and other cities, after continuous rainstorm, urban streets turned into fishponds, causing casualties and vehicle damage.

In recent 5 years, the application of mobile Internet in emergency management has increased at home and abroad. In September 2017, Mexico experienced a major earthquake. The Mexico government updated the existing emergency smart phone application (App), adding the function of sending earthquake alerts. The mobile phone application, called "911CDMX", was developed by the C5 information monitoring center of the government. Both Apple iOS and Android mobile operating systems could download the system free of charges. Its functions included browsing earthquake related micro-blogs, contacting first aid operators, and uploading information like blood types and medical records. Through this application, people could get the most accurate and timely rescue when they were in danger. In Guizhou Province of China, the traffic police also launched an APP, which allowed people to upload video or photos about illegal driving acts like occupy emergency lanes when they driving. After verification, citizens could get mobile phone calls recharge. 
At present, empirical researches on emergency management mainly focus on the usage of social media in disasters, especially the prevention and response functions of micro-blog and WeChat in emergency management. Studies on emergency alarm system targeted on particular kind of events, such as problems in telecommunication and electric power systems can also be found. There is no research on the emergency alarm system which can integrate various relevant departments in case of public emergencies.

The focus of this paper is to use the interactive Internet platform to establish a public emergency alarm platform which integrates public services such as public security, medical first aid, fire alarm, sanitation, power supply, water supply and gas supply. Through this platform, timely and effective communication can be achieved to improve the speed of emergency response. The platform links experts, victims and volunteer groups; it is conducive to the sharing of knowledge and experience from individuals and organizations. Group wisdom can be generated through this cooperation process. Group wisdom has great application value in unexpected events (especially unconventional emergencies); large scale collaboration can help to solve complex problems and make group decisions as well as predictions.

\section{Current Dissemination Channels of Government Emergency Information}

At present, the government can release emergency information through television, newspapers, government websites and social networks. A considerable number of government departments have applied official micro-blog accounts in Sina micro-blog and the Tencent micro-blog platforms. Some government department accounts which are close to public daily life have attracted many followers. For instance, Pingan Beijing has become an influential self media account with 12461355 fans. The government's response to Internet new media has gradually changed from the "blocking and suppressing" method to an open, communicative and cooperative management mode. The government began to play its role in the development and controlling of social network and contributes to the global network governance. I am totally agreed that government departments should occupy their positions in social media. If they fail to that, they will be in the inferiority of public supervision; when are forced to prove their innocence under the pressure of public opinion, it will be difficult for them to get trust from the public.

CNNIC data showed that by June 2017, the proportion of mobile phone users reached $96.3 \%$ in Chinese netizens, increased by 1.2 percentage points compared with the end of 2016. The number was higher than the global average level. China's status as an Internet behemoth is beyond doubt. How to use new technologies more effectively and do well in information communication in emergency management is an issue which needs concerns from various levels of governments.

\section{Social Media has become the Main Platform of Government Emergency Information Distribution}

In recent years, the value of social media in emergency management has been noticed at home and abroad, since it can help to realize real-time monitoring of natural disasters, as well as large-scale searches and rescue operations. In the current social networking environment, ordinary citizens have become information providers. In the past, general citizens can provide limited information about the disaster. Now, the social network platform has become a very powerful communication tool which can help the government to establish a better response mechanism.

Government departments of our country have made great strides in information communication based on Internet. Government information disclosure systems have been established; relevant departments at all levels of the government have launched network news spokesperson system. But the government-public communication mode still needs to be improved. The main reason is the influence of "official rank standard" thought formed under the planned economy system. The government departments focus on management rather than service, and attach less importance to the necessity of administrative openness. Due to the fragmentation of government institutions, communications between departments are not enough. Departmental interest conflicts and regional 
conflicts often occur. Some departments even refuse to share the information. In accordance with the law, information disclosure and publication are necessary; but in essence, they are responses to public events afterwards. Some government departments have created WeChat and micro-blog accounts. But the usage of these accounts is limited in the most basic applications, or the electronization of official paper media. The contents are too simple. For example, the management of Tanggu explosion in Tianjin was disordered; information communication among departments was not smooth. Five days later, the news spokesman even did not know who was the commander of the emergency management. Environmental monitoring of dangerous chemicals after the explosion was almost like a joke; information released by official agencies contradict with each other. In short, the government is still in a relatively passive position in emergency communication.

Today, the widely usage of social media brings more supervision on governments' crisis management. Some defective or wrong crisis responses will be exaggerated by the Internet and bring great challenges to the public credibility of the government. The previous government information communication method cannot adapt to the crisis communication in the Internet era.

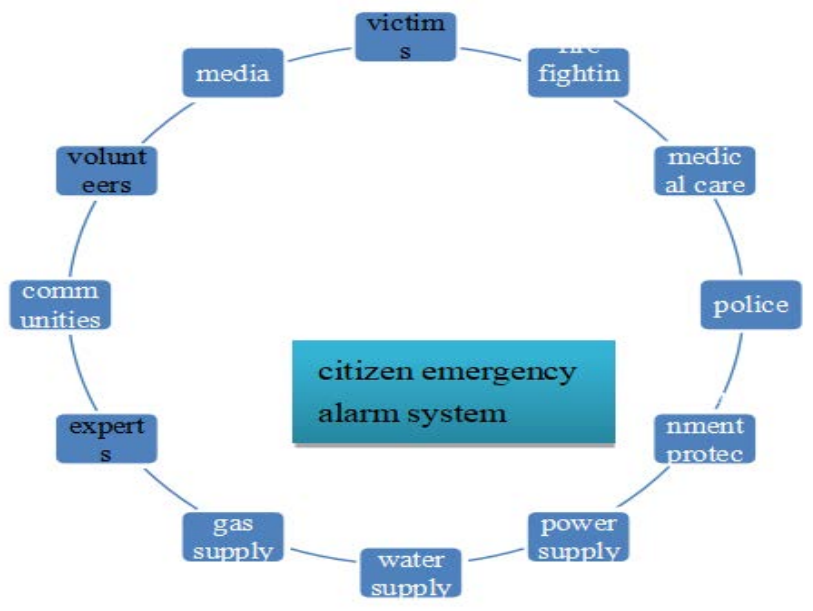

Figure 1. The communication model of citizen emergency alarm system

\section{Change the Passive Citizen Emergency Alarm Model to an Active One}

The emergency alarm system (Figure 1) is two-way platform. Disaster victims can post information in the emergency alarm system for the first time. Emergency response agencies can share and exchange information directly on the platform. The government should quickly publish investigation processes, release the truths, and maintain continuous and transparent communication with citizens; these measures will help to alleviate the social psychological pressure caused by crises. For example, in the case of explosion, the medical department should immediately organize hospitals to allocate manpower and material resources according to the disaster situation. On-site firefighters can use this platform to share pictures, videos and other information with dangerous products experts. According to the information, experts can judge the dangerous and destructive degrees of dangerous objects, which will make the disaster relief process more effective. The emergency response department of the environmental sanitation sector should immediately act with experts to investigate the cause of the accident and study the solution. They should publish the property and quantity of explosive materials, as well as possible consequences to surrounding environment and air, and let citizens know the true situation. Through this unified information sharing platform, affected residents can learn the distribution of the wounded in nearby hospitals as well as the medical treatment abilities of hospitals, and make best medical decisions. Volunteer organizations can learn how to provide the most needed services from this platform.

\section{The Necessity of Citizen Emergency Alarm System}

In the present social network environment, the disaster information firstly comes from social 
network information posted by residents in the affected area. The explosion in Tanggu, Tianjin is an example. The public got latest information about the disaster from pictures and videos posted on the Internet. Through there were information about the disaster stricken areas, the damage of buildings the injury of people, the government did not use these social media information effectively to cope with the crisis. Rescue operations reports were still released through news conferences, televisions, newspapers and websites, though more effective and timely transmission of real time information can be achieved through social media. If the government established an emergency alarm system and trained the public to use it, it would be able to seize the initiative and improve the speed of disaster response.

From the angle of the government, the public emergency alarm system is a mobile Internet based information platform; it can collect, analyze, store and output information in all directions. On the basis of comprehensive, rapid, timely and accurate information, the government can make scientific decisions and formulate effective management procedures; the scientific level of government's crisis management can be improved. During emergency events, the platform provides local residents with information and emergency guidance, allows them upload information like photos and videos through computers or mobile communications equipment such as mobile phones and tablets. Residents are allowed to report disasters such as mountain torrents, tornadoes, hurricanes, public health events and terrorist attacks. Emergency response personnel analyze submitted information and send emergency response information to residents through mobile phones, e-mails or mobile Internet devices.

The system collects and analyzes a large amount of information about the crisis, such as data of terminal monitoring and crisis rescue, anti-epidemic measures and psychological intervention methods in the recovery stage, as well as the features and summaries of the crisis, so as to improve the efficiency of crisis response. After the crisis, the government crisis response agencies need to understand the situation and development of the crisis, in order to formulate timely and effective solutions. For example, when a crisis occurs, the government should set data monitoring equipment in the affected area. For instance, after the Tanggu explosion of Tianjin, the qualities of air, water and soil should be detected dynamically. Some monitoring points should be set up at the beginning of rescue operation, in order to collect and analyze data about the air, water and other related areas every day. Reports on air, water and soil qualities can play an important role in post-disaster reconstruction and soothing disaster victims. Establishing a dynamic monitoring system is the main link of crisis information management. This link mainly includes data collection and display, as well as interest and data recording. The data collection should be accurate, complete and timely; the contents should include disaster assessment, crisis rescue workers and resources allocation, as well as material distribution and shortage levels. The rescue information can be combined with the onsite coordination system, and provides references to crisis management personnel in decision-making through display equipment. Through data processing, the configuration of various resource can be optimized.

The citizen emergency alarm system should include all kinds of media. Crisis events arouse public concern and have great impacts on regional economic development as well as people's thinking and behavior modes. Emergencies are hot spots and foci of social attention in a short period of time. Effective and timely reports on emergency events can help the government to cope with dangerous situations and realize post-crisis reconstruction. Media are information disseminators which play a great role in guiding people's thinking and behaviors. Government departments must use the media correctly, making them participate in crisis management and play an active role, in order to guarantee the smooth emergency management of the government. According to the arrangement of the command and coordination center, the media can summarize rescue information, and tell victims where they can get food, tents and medical service; they can also tell volunteers where they can find people in need, and organize citizens to save themselves. The media should also take the responsibility of mobilizing all walks of life to participate in donation and transportation, guiding public opinions, and directing emergency materials and qualified medical products to flow into the emergency logistics center. The media should be closely combined with the government and guide 
the public to correctly participate in rescue operation. Thus, the media can play a positive role in emergency management.

The main purpose of this citizen emergency alarm system is that, in emergencies, all involving parties can share information through this system. It includes both the release of government information and the collection of public opinions on crisis response. Through this integrated emergency information system, the government can release authoritative information to reduce the spread of negative information such as rumors. At the same time, disaster victims also provide the government with another information collection channel, which will help the government to stay close with the people. The citizen emergency system should give full play to social media's functions like early warning, crisis information transmission, rescue participation and guidance, as well as supervision and evaluation services, and form the positive information distribution mechanism in crisis management.

\section{Conclusion}

The main purpose of this citizen emergency alarm system is that, in emergencies, all involving parties can share information through this system. The government should recommend this emergency alarm system to the public, so as to take the initiative in emergency response, integrate powers from all walks of life, combine early warning services, crisis information transmission, rescue participation and guidance, as well as supervision and evaluation services together, and give full play to the government's powerful coordination and organization abilities.

\section{References}

[1] J.M. Wu, Application of social media in the government, corporate guide, J. Guide to Business. 8 (2011).

[2] X.L. Lv, Government emergency management and information communication in the Web2.0 era, J. Disaster Reduction in China. 5 (2010)

[3] Y. Feng, Study on the government information publicity in natural disasters emergency management, 2009.12.1

[4] Q.Y. Kuang, Research on the role of social media in catastrophe risk management, 2014

[5] J. Xu, Opportunities and challenges brought by social media to government crisis communication and risk communication, J. Social Sciences in Nanjing. 5 (2013).

[6] Z.J. Xia, Z. Wu, D.Q. Luan, Summary of research on emergency information sharing based on social media, J. Journal of Intelligence. 10 (2013).

[7] L.D. Chen, Q.H. Yu, The implementation of Governmental Information Publicity in reports of Wenchuan earthquake, J. Today's Massmedia. 7 (2008).

[8] H.L. Nie, to ensure information disclosure and civil knowing in emergency processing, J. Legal System and Society. 15 (2008).

[9] W.X. Yang, Dissemination of information in emergencies: take Wenchuan earthquake as an example, J. Lanzhou Academic Journal. 51 (2008).

[10] X.Y. Li, Implementation of CMAS commercial mobile early warning system in LTE, J. Telecommunications Information. 04 (2015).

[11] J. Teng, Fire and disaster prevention SCM automatic monitoring system in residential areas, J. Journal of Taiyuan Urban Vocational College. 02 (2005).

[12] Y.T. Guo, Research on Application of IOT in the Field of Safety and Emergency for Urban Rail Transit, Beijing Jiaotong University, 2011. 